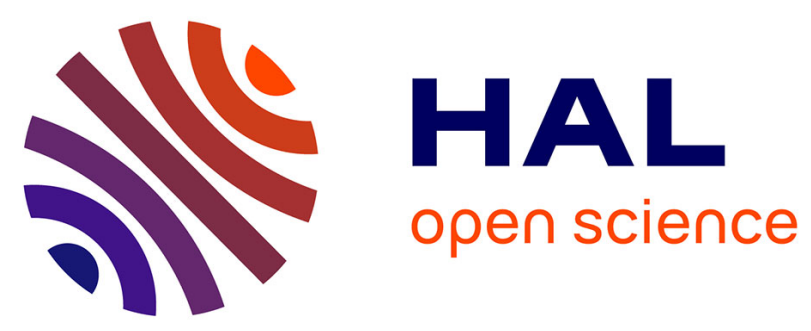

\title{
Formation and crystallography of nano/ultrafine-trimorphic structure in metastable $\beta$ titanium alloy Ti-5Al-5Mo-5V-3Cr-0.5Fe processed by dynamic deformation at low temperature
}

Jiangkun Fan, Jinshan Li, Yudong Zhang, Hongchao Kou, Lionel Germain, Claude Esling

\section{To cite this version:}

Jiangkun Fan, Jinshan Li, Yudong Zhang, Hongchao Kou, Lionel Germain, et al.. Formation and crystallography of nano/ultrafine-trimorphic structure in metastable $\beta$ titanium alloy Ti-5Al-5Mo$5 \mathrm{~V}-3 \mathrm{Cr}-0.5 \mathrm{Fe}$ processed by dynamic deformation at low temperature. Materials Characterization, 2017, 130, pp.149-155. 10.1016/j.matchar.2017.06.005 . hal-02483351

\section{HAL Id: hal-02483351 \\ https://hal.science/hal-02483351}

Submitted on 18 Feb 2020

HAL is a multi-disciplinary open access archive for the deposit and dissemination of scientific research documents, whether they are published or not. The documents may come from teaching and research institutions in France or abroad, or from public or private research centers.
L'archive ouverte pluridisciplinaire HAL, est destinée au dépôt et à la diffusion de documents scientifiques de niveau recherche, publiés ou non, émanant des établissements d'enseignement et de recherche français ou étrangers, des laboratoires publics ou privés. 


\title{
Formation and crystallography of nano/ultrafine-trimorphic structure in metastable $\beta$ titanium alloy Ti-5Al-5Mo-5V-3Cr-0.5Fe processed by dynamic deformation at low temperature
}

\author{
Jiangkun Fan ${ }^{\mathrm{a}, \mathrm{b}, \mathrm{c}, *}$, Jinshan $\mathrm{Li}^{\mathrm{a}}$, Yudong Zhang ${ }^{\mathrm{b}, \mathrm{c}}$, Hongchao Kou ${ }^{\mathrm{a}}$, Lionel Germain ${ }^{\mathrm{b}, \mathrm{c}}$, \\ Claude Esling ${ }^{\mathrm{b}, \mathrm{c}}$ \\ a State Key Laboratory of Solidification Processing, Northwestern Polytechnical University, Xi'an 710072, PR China \\ b Laboratoire d'Étude des Microstructures et de Mécanique des Matériaux (LEM3), CNRS 7239, Université de Lorraine, 57045 Metz, France \\ ${ }^{\mathrm{c}}$ Laboratory of Excellence on Design of Alloy Metals for low-mAss Structures (DAMAS), Université de Lorraine, 57045 Metz, France
}

\section{A R T I C L E I N F O}

\section{Keywords:}

Titanium alloy

Phase transformation

Nano/ultrafine-trimorphic

Variants selection

Ti-5553

\begin{abstract}
A B S T R A C T
The dynamic $\beta \rightarrow \alpha$ phase transformation of metastable $\beta$ titanium alloy Ti-5553 during the hot deformation process was investigated, including the crystallographic orientation relationship between $\alpha$ phase and $\beta$ matrix and the variant selection mechanism of nanoscale $\alpha$ precipitates. It is revealed that nano/ultrafine-trimorphic structure can be successfully produced dynamically Ti-5553 alloy through warm compression without severe plastic deformation or subsequent aging treatment. Ultrafine equiaxed $\alpha / \beta$ grains do not respect Burgers orientation relationship were observed in the slip bands together with the remaining regions consisting of the lamellar $\alpha$ structure maintaining the Burgers orientation relationship with $\beta$ matrix. Moreover, the irregular $\alpha$ grains were mainly attributed to the fragmentation of $\alpha$ lamellae in some areas. There was variation in the proportion and distribution of the precipitates in the different areas depending on deformation. Furthermore, the strain induced variant selection of $\alpha$ I happened drastically.
\end{abstract}

\section{Introduction}

Over the last decades, structural applications of metastable $\beta$ titanium alloys have always been popular in the aerospace industry because of their higher yield strength, better hardenability, better fatigue and crack propagation properties than $\alpha+\beta$ titanium alloys, in which strengthening by grain refinement and precipitation of fine $\alpha$ phase yields similar strength levels as low alloyed and even some stainless steels $[1,2]$. Microstructural development in these alloys is sensitively linked to a range of processing parameters, such as route of thermomechanical process (TMP), temperature and strain. In general, fine or even nanostructured materials are expected due to the superior mechanical properties could be obtained. Hence, extensive efforts have been devoted to the ultrafine microstructure and its evolution of titanium alloys related to various thermomechanical processes in the past decades owing to their considerable scientific and practical interest [3-6].

The distribution and morphology of $\alpha$ precipitates in the microstructure largely depend on the nucleation mechanism. In the $\beta$ phase matrix, $\alpha$ precipitates can nucleate either homogeneously or heterogeneously. The homogeneous nucleation of $\alpha$ phase involves a pseudo-spinodal decomposition of the metastable $\beta$ phase, which leads to small compositional fluctuations in the matrix [7]. On the other hand, nucleation of $\alpha$ phase can occur heterogeneously at grain boundaries, subgrain boundaries, dislocations or precursors such as $\omega$ phase, $\beta^{\prime}$ phase or martensite [8-10]. The $\alpha$ phase formed during the heat treatment process generally possess platelet morphology in metastable $\beta$ titanium alloys. To obtain the fine multi-morphology structure, deformation must be considered necessarily. A commonly adopted approach is the introduction of severe plastic deformation prior to aging, thus ultrafine-duplex $(\alpha+\beta)$ structure attributed to the $\alpha$ nucleation at abundant crystal defects would be obtained. S.L. Semiatin et al. [11] have also shown that the final grain size and the required strain can be significantly reduced through lowering the deformation temperature and/or utilizing a finer initial microstructure (i.e., reducing the $\alpha$ platelet thickness in particular). Nevertheless, the nano/ultrafine-trimorphic structure has never been reported in previous researches of metastable $\beta$ titanium alloys. Furthermore, none of studies have identified the exact locations of the different morphologies respectively, nor have they clarified its dependence on deformation

\footnotetext{
* Corresponding author at: 127 Youyi West Road, Xi'an, Shaanxi 710072, PR China.

E-mail address: jkfan@nwpu.edu.cn (J. Fan).
} 


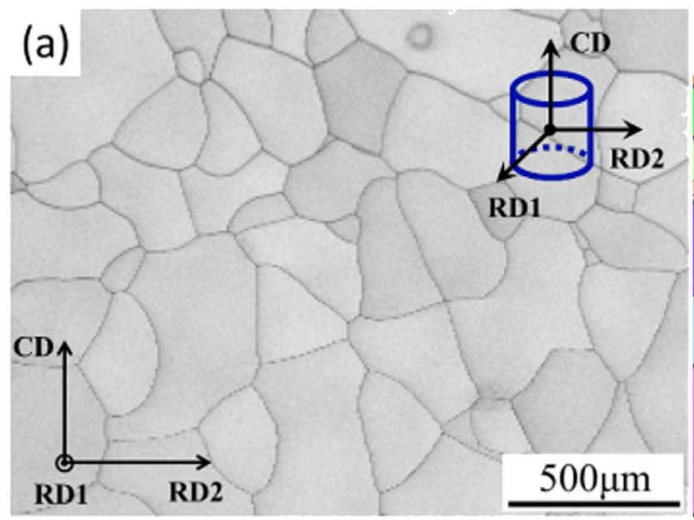

(c)
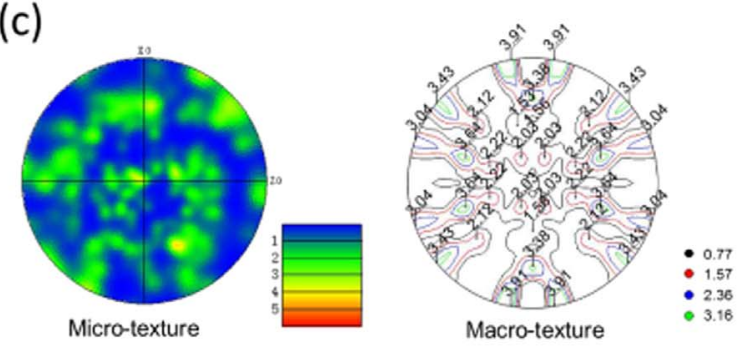

parameters. In addition, R. Shi et al. [12] found that, for a given undercooling, the development of a transformation texture (also called microtexture) of the $\alpha$ phase due to variant selection during precipitation is determined by the interplay between externally applied stress or strain and internal stress generated by the precipitation reaction itself. M. Klimova et al. [13] have found that the average deviation from the Burgers orientation relationship (BOR) [14] reaches a value of $34.5^{\circ}$ at a strain of 1.2 in Ti-5Al-5Mo-5V-1Cr-1Fe. Therefore, hot deformation process could give a significant effect on the $\alpha$ variant selection mechanism and $\alpha / \beta$ crystallographic orientation.

In our present work, the low temperature compressive deformation was performed on the typical metastable $\beta$ titanium alloy Ti-5Al-5Mo$5 \mathrm{~V}-3 \mathrm{Cr}-0.5 \mathrm{Fe}$ (Ti-5553) with single $\beta$ initial microstructure. The dynamic $\beta \rightarrow \alpha$ phase transformation behavior during the hot deformation was investigated, including microstructure evolution and variant selection mechanism of nanoscale $\alpha$ precipitates. The results could provide a valuable understanding of the interrelation between phase transformation and thermomechanical processing.

\section{Materials and Research Methodology}

The as-received material of the present study is $(\alpha+\beta)$ forged Ti5553 bar with chemical composition (wt\%) of Al: 5.26; Mo: 4.99; V: 4.80; Cr: 2.86; Fe: 0.42; Ti: balance. The $\beta$ transus temperature of Ti5553 alloy determined by metallographic analyses is approximately $870{ }^{\circ} \mathrm{C}$. Cylindrical specimens, $10 \mathrm{~mm}$ in diameter and $15 \mathrm{~mm}$ in height, were machined from the forged bar. They were then solution treated at $900{ }^{\circ} \mathrm{C}$ for $30 \mathrm{~min}$ followed by water quenching in order to obtain single $\beta$ phase state with homogeneous microstructure. The macro-texture of the initial microstructure was measured by using Brüker D8 Advance XRay Diffraction (XRD). Cu Ka $(\lambda=1.5418 \AA)$ was used, under $40 \mathrm{kV}$ and $40 \mathrm{~mA}$.

Uniaxial hot compression test was carried out with a Gleeble-3500 thermo-mechanical simulator along the cylindrical axis of the specimen. Prior to compression, each specimen was heated to the processing temperatures at a rate of $25{ }^{\circ} \mathrm{C} / \mathrm{s}$ and then held for $10 \mathrm{~s}$ before the commencement of compression to ensure an establishment of homogeneous temperature field in the specimen. The temperature was controlled by a thermocouple welded to the central part of the specimen
Fig. 1. (a) EBSD band contrast micrograph of the single $\beta$ phase initial microstructure; (b) EBSD CD axis Inverse Pole Figure (IPF) micrograph; (c) Micro- and macro- $\{110\}$ pole figures; (d) Correlated misorientation angle distribution. surface. Graphite lubrication was applied to the anvil and the specimen in order to reduce the relative friction between the two parts to enhance deformation homogeneity and also to prevent adhesion. The temperature $\left(600{ }^{\circ} \mathrm{C}\right)$, strain rate $\left(0.001 \mathrm{~s}^{-1}\right)$ and deformation strain $(0.7)$ were automatically controlled and recorded by the Gleeble-3500 thermal simulator system.

The deformed specimens were sectioned parallel to the compression axis and all microstructural and crystallographic characterizations were performed on this specimen section. For SEM (JSM-6500F) observations and EBSD measurements (OXFORD EBSD acquisition camera and the OXFORD-AZTEC online acquisition software), the specimens were first mechanically polished and then electro-polished with a solution of $20 \%$ perchloric acid in methanol under a voltage of $35 \mathrm{~V}$ at $10{ }^{\circ} \mathrm{C}$ for $6 \mathrm{~s}$. And then they were etched in a modified Kroll's reagent of $10 \mathrm{vol} \% \mathrm{HF}$, 10 vol\% HNO3 and 80 vol\% H2O for 10 s. For TEM (Philips CM200 operated at $200 \mathrm{kV}$ ) analyses, foil specimens were prepared first by mechanical thinning to about $80 \mu \mathrm{m}$ in thickness. Then discs with $3 \mathrm{~mm}$ in diameter were punched off and further thinned to be electron transparent by twin-jet electro-polishing using a Struers Tenupol-5 twin-jet electropolisher in a solution of $20 \%$ perchloric acid in methanol under $10 \mathrm{~V}$ at $-35^{\circ} \mathrm{C}$. The orientations of the $\alpha / \beta$ grains of the two phases were determined from the Kikuchi patterns produced under the convergent electron beam with the home made orientation determination software package Euclid Phantasies (EP) $[15,16]$ and represented with a triplet of Euler angles in Bunge notation [17].

\section{Results and Discussion}

\subsection{Initial Microstructure of Ti-5553 Alloy}

The initial single $\beta$ microstructure obtained by solution treatment at $900{ }^{\circ} \mathrm{C}$ for 30 min followed by water quenching, as shown in Fig. 1(a), is composed of single $\beta$ phase with an average grain size of $\sim 300 \mu \mathrm{m}$ in equiaxed shape. Except for few low angle grain boundaries (LAGBs, $2^{\circ}-10^{\circ}$ ), almost all of the $\beta$ grains are surrounded by high angle grain boundaries (HAGBs, $>10^{\circ}$ ) (Fig. 1(b)). The correlated misorientation angle distribution histogram in Fig. 1(d) displays that the initial microstructure possesses a disorientation angle distribution close to that of randomly oriented polycrystals (the line profile), suggesting that the 


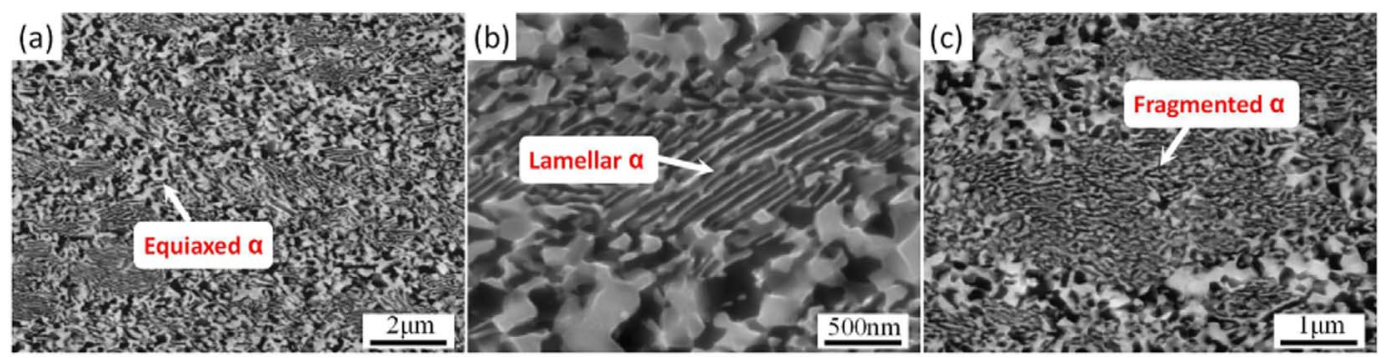

Fig. 2. SEM micrographs of the nano/ultrafine-trimorphic structure in the central area of the deformed Ti-5553 alloy: (a) equiaxed $\alpha$; (b) lamellar $\alpha$; (c) fragmentized $\alpha$.

alloy is probably not sharply textured. That is consistent to the implication of the micro/macro $\{110\}$ pole figures in Fig. 1(c).

\subsection{Nano/Ultrafine-Trimorphic Structure and Orientation Relationship}

The microstructural observation of the center of the deformed specimen using SEM/TEM shows in Fig. 2. Obviously, three different morphologies of $\alpha$ phase could be detected simultaneously in the center, i.e., equiaxed $\alpha$ grains $(50-200 \mathrm{~nm}$ ) (Fig. 2(a)), lamellar $\alpha$ $(\sim 20 \mathrm{~nm}$ in width) (Fig. 2(b)) and fragmentized $\alpha$ grains $(\sim 20 \mathrm{~nm})$ (Fig. 2(c)). What needs to be stressed is that all of the various $\alpha$ phase precipitated dynamically during the compression test. The equiaxed microstructure seems form irregular net which filled by the lamellar and fragmentized $\alpha$ (Fig. 2(a)).

Further TEM micrographs and SAED patterns are shown in Fig. 3. The equiaxed constituents consist of mixed fine $\alpha$ and $\beta$ grains. The SAED pattern of the fine equiaxed microstructure shows that the $\alpha / \beta$ reflections tend to form arcs, suggesting the random crystallographic orientations between $\alpha / \beta$ phases (Fig. 3(a)). For the lamellar constituents, they are composed of alternatively distributed $\alpha$ and $\beta$ platelets, maintaining BOR $\left(\{0001\}_{\alpha}\left\|\{110\}_{\beta},\langle 11 \overline{2} 0\rangle_{\alpha}\right\|<111>_{\beta}\right.$ [14]), as shown in Fig. 3(b). The SAED pattern indicates that the $\alpha$ lamellae in one colony possesses the unique crystallographic orientation.

To investigate the orientation relationship (OR) between the fine $\alpha$ and $\beta$ phases in the equiaxed constituents zones, the deformed specimens was further studied by TEM electron diffraction under the convergent beam. Fig. 4 is a TEM bright field image of the equiaxed $\alpha$ and $\beta$ grains. The orientations of the $\alpha / \beta$ grains of the two phases were determined from the Kikuchi patterns produced under the convergent electron beam with the home made orientation determination software package Euclid Phantasies (EP) [15,16] and represented with a triplet of Euler angles in Bunge notation [17]. The table in Fig. 4 shows the Euler angles of the $\alpha$ and $\beta$ grains indicated in the TEM bright field micrograph. The pole figures of the adjacent three $\beta$ grains and the four $\alpha$ grains are displayed in the Fig. 5. Unfortunately, no ORs including the typical BOR could be found between the adjacent $\beta$ and $\alpha$ grains.
Whereas, compared with the case of heat treatment process [3], all the $\alpha$ phase (grain boundary $\alpha$ and intragranular $\alpha$ ) generally maintains the BOR with the $\beta$ matrix. Obviously, the external hot deformation has a significant influence on the obeying of BOR during $\beta \rightarrow \alpha$ phase transformation.

\subsection{Variation of Microstructure in the Compression Disc}

Fig. 6 shows the variation of precipitation morphologies along the compression disc radius and thickness. In the area along the thickness near the edge of the specimen (denoted by A), except for fine equiaxed $\alpha$ grains $(\sim 150 \mathrm{~nm})$ nuclear at the initial $\beta$ grain boundaries, the dense cluster of ultrafine $\alpha$ lamellae $(\sim 20 \mathrm{~nm}$ in width) forming as colonies distributed in the $\beta$ grains (Fig. $6\left(\mathrm{a}_{1}\right)$ ). This proves that area $\mathrm{A}$ has experienced relatively limited deformation during deformation. Meanwhile, only two or three $\alpha$ variants with different crystallographic orientations distributed in one $\beta$ grain (Fig. $6\left(a_{2}\right)$ ). In the area along the thickness near the central of the specimen (denoted by B), the straight multi-slip bands are formed significantly and the microstructure consisted of both fine equiaxed $\alpha / \beta$ grains and the $\alpha$ lamellae structure (Fig. $6\left(b_{1}\right)$ ). The equiaxed and parallel lamellar $\alpha$ precipitates are formed inside and outside the slip bands, respectively (Fig. $6\left(b_{2}\right)$ ). Straight multi-slip bands and equiaxed grains as well as fragmented $\alpha$ platelets are also easily fund in the area of C (Fig. 6( $\left.\mathrm{c}_{1-2}\right)$ ) (similar to B). For area $\mathrm{D}$, the microstructure is kinked but no more significant slip bands (Fig. $6\left(\mathrm{~d}_{1-2}\right)$ ). The characteristics of $\mathrm{B}$ and $\mathrm{C}$ are closer to the central microstructure, which contributed to the relatively larger strain applied to B/C than A/D. In general, the nearer to the central of specimen, the easier to obtain a nano/ultrafine-trimorphic structure. Actually, the irregular equiaxed microstructure nets in central area are the result of drastic kinking and accumulation of slip bands during deformation. All $\alpha$ platelets distributed as certain directions, i.e., the $\alpha$ variants were selected severely, which is totally different from the $\alpha$ platelet precipitates usually nucleate and eventually form a basketweave structure in the metastable $\beta$ titanium alloys $[18,19]$.
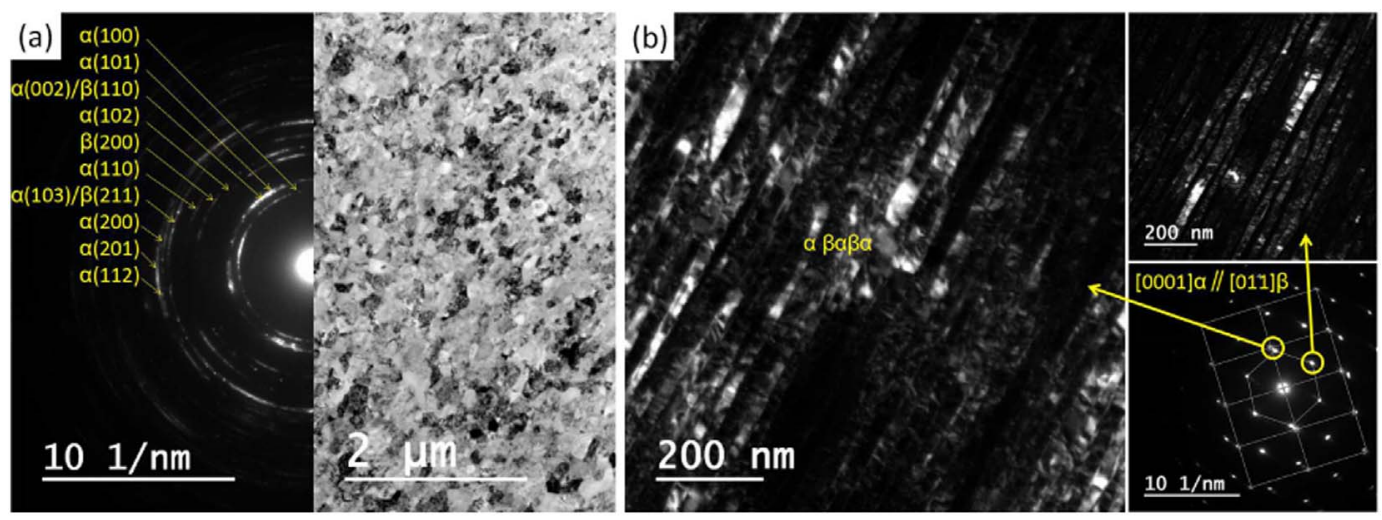

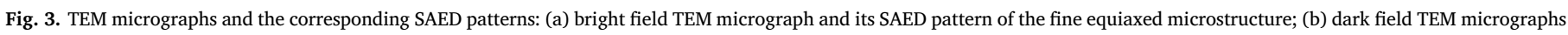
and its SAED pattern of the $\alpha / \beta$ lamellae microstructure. 


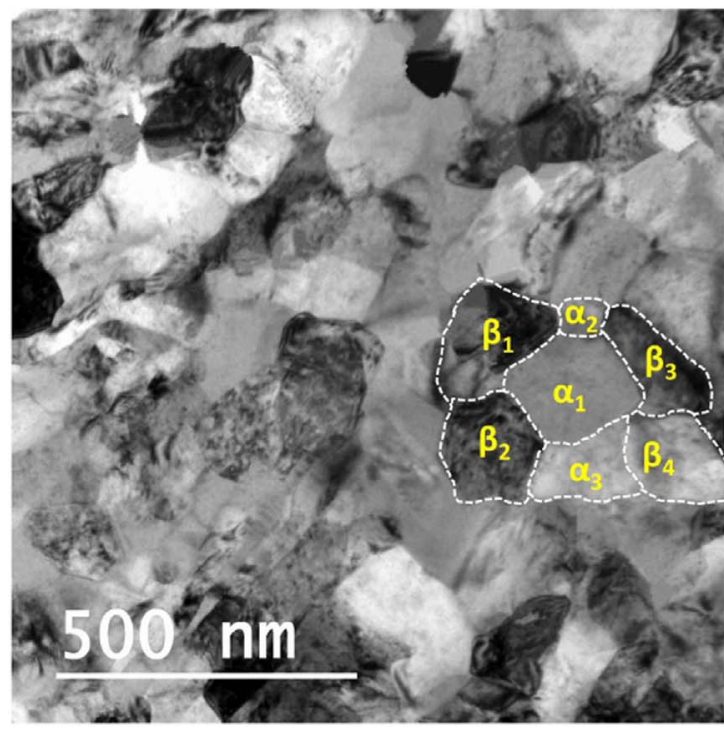

\begin{tabular}{|cc|}
\hline Grain & Euler angle $(\varphi 1, \Phi, \varphi 2)$ \\
\hline$\alpha_{1}$ & $280.17,50.44,260.50$ \\
\hline$\alpha_{2}$ & $162.47,39.50,179.71$ \\
\hline$\alpha_{3}$ & $140.81,88.80,210.79$ \\
\hline$\alpha_{4}$ & $220.49,66.62,270.55$ \\
\hline$\beta_{1}$ & $132.80,19.47,130.90$ \\
\hline$\beta_{2}$ & $160.64,4.50,55.26$ \\
\hline$\beta_{3}$ & $199.68,77.24,320.93$ \\
\hline
\end{tabular}

Fig. 4. TEM bright field micrograph of the equiaxed $\alpha$ and $\beta$ grains and the corresponding Euler angles of the marked $\alpha$ and $\beta$ grains with dotted line in the micrograph.

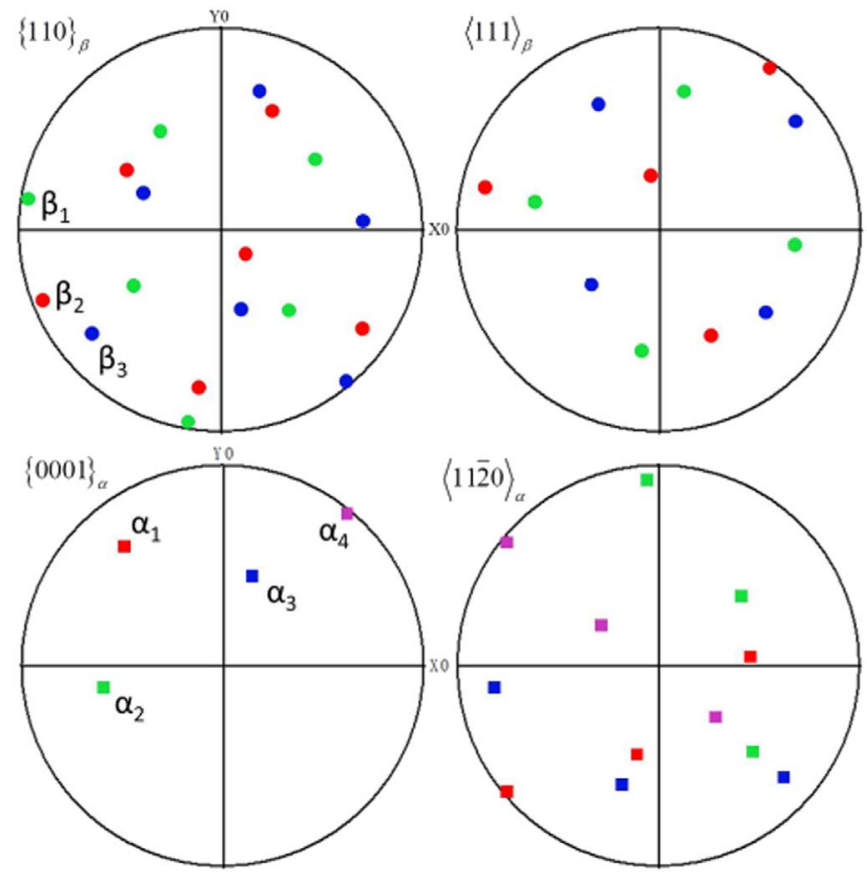

Fig. 5. $\left.\{110\}_{\beta} /<111\right\rangle_{\beta}$ and $\left.\{0001\}_{\alpha} /<11 \overline{2} 0\right\rangle_{\alpha}$ plane/direction pole figures of the three $\beta$ grains and the four $\alpha$ grains selected in Fig. 4.

\subsection{Variant Selection Mechanism of $\alpha$ Phase}

All the $12 \alpha$ variants would nucleate with equal probability during $\beta \rightarrow \alpha$ phase transformation in an ideal case, as shown in schematic diagram Fig. 7(a). The different colors in Fig. 7 represent corresponding $\alpha$ variants, respectively. One can detect up to $12 \alpha$ variants in one $\beta$ grain theoretically [20]. Therefore, in the present results, the only reason of just two or three orientations of $\alpha$ lamellae formation during the deformation must be the strong variant selection. For instance, the $\alpha_{\mathrm{V} 1}$ (red) and $\alpha_{\mathrm{V} 2}$ (green) in the one deformed $\beta$ grain (Fig. 7(b)). The present variant selection of intragranular $\alpha\left(\alpha_{\mathrm{I}}\right)$ during the dynamic precipitation is determined by the interplay between externally applied stress $\left(\sigma^{e x}\right)$ and internal stress generated by the phase transformation $\left(\sigma^{t r}\right)[12,21]$. Thus, the composite stress $\left(\sigma^{c o m}\right)$ must be considered in the present work. When a coherent or semi-coherent crystallographic orientation is formed during the phase precipitation process, the elastic strain will be built up by lattice misfits between the second phase and matrix. Definitely, the application of an external directional elastic stress may cause contraction or expansion along the precipitating habit planes, which will lead to either enhancement or release of the misfit strain. The energy change caused by the variations of the misfit strain is the interaction energy between external stress and the stress field of the misfitting precipitate. The variations of the interaction energy of different variants of precipitate have been quantitatively analyzed with respect to external stress direction in the frame of Eshelby's elastic inclusion model [22]. On the other hand, the volume change under external stress during the precipitated platelets replacing the matrix materials contributed to the variation of potential energy of system [23]. Whereupon potential energy change from the volume change under external stress could be expressed as

$\Delta G_{E}^{e x}=\sigma \cos \theta \Delta V$

where $\theta$ is the angle between the external stress axis and the $\alpha$ platelet normal, as shown in Fig. 7 (c). $\Delta V$ is the volume change during the $\beta \rightarrow$ $\alpha$ phase transformation.

In addition, the interaction energy between external stress and the stress field of the misfitting interface of $\alpha / \beta$ could be expressed as [23]

$\Delta G_{E}^{t r}=\sigma \cos \theta V_{\alpha} \varepsilon$

where $V_{\alpha}$ is the volume of alpha precipitate, $\varepsilon$ is the coherency strain between $\alpha / \beta$. Therefore, the potential energy change of different $\alpha$ platelet variants differs from each other due to different $\theta$ values with stress axis, expressed as

$$
\begin{aligned}
\Delta G= & V_{\alpha} \Delta G_{V}+A \Delta G_{R}+\Delta G_{E}^{e x}+\Delta G_{E}^{t r}=V_{\alpha} \Delta G_{V}+A \Delta G_{R} \\
& +\sigma \cos \theta\left(\Delta V+V_{\alpha} \varepsilon\right)
\end{aligned}
$$

where $\Delta G_{V}$ and $\Delta G_{R}$ are the volumic free energy change and interfacial energy and elastic strain energy respectively. $A$ is the $\alpha$ phase surface area. The $\alpha$ variant with the most favorable $\theta$ value will get the largest decrease of potential energy and priority to nucleate and grow (Fig. 7(c)), which resulting in only several $\alpha$ variants were selected.

\subsection{Microstructure Evolution of Ti-5553 Alloy During the Hot Deformation Process}

As mentioned above, all of the slip bands are occupied by fine equiaxed $\alpha$ and $\beta$ grains, while irregular fragmentized $\alpha$ particles and parallel $\alpha$ lamellae are distributed in the gaps between the bands. Because the initiation of the slip bands produced by dense dislocations is accompanied by the nucleation of $\alpha$ phase during the hot deformation, the slip bands would be the preferential nucleation sites [24]. 

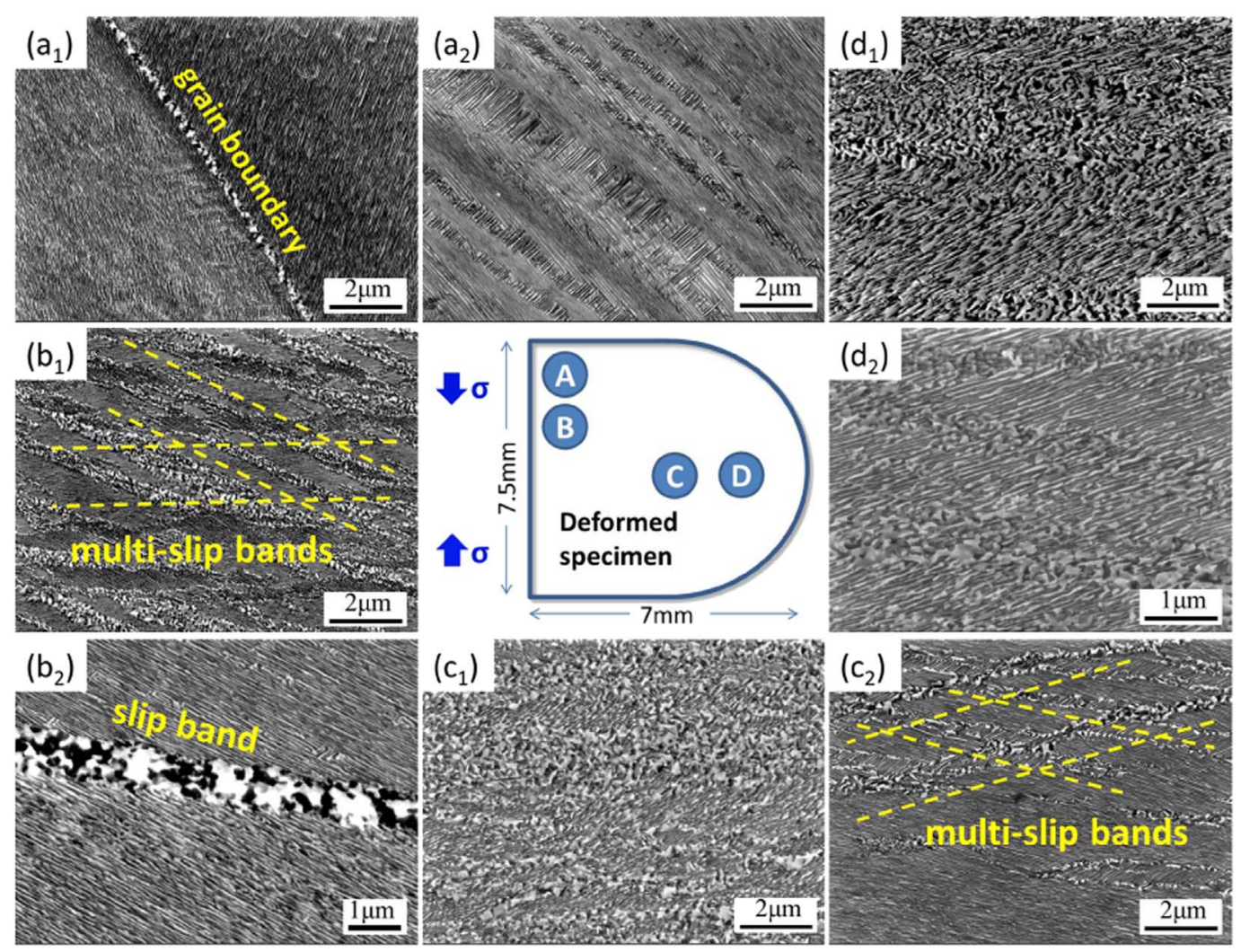

Fig. 6. Variation of precipitation morphologies along the compression disc radius and thickness.

Abundant cumulate dislocations and the drastic lattice rotation in the bands would result in $\alpha$ nuclei growing up to a fine equiaxed structure, as Fig. 8(a) shows. These precipitates underwent a rotation and increased misorientations to accommodate the continuous strain (Figs. 4-5). Subsequently, both the size of $\alpha$ particles and the width of slip bands would increase gradually with the increased strain. Another important point is that the diffusion rate of alloy elements is faster at GBs and slip bands, which would contribute to the nucleation and growth of $\alpha$ phase $[25,26]$. That is why the size of $\alpha$ precipitates on slip bands and GBs is larger than the width of $\alpha_{I}$ platelets.

On the other hand, the $\alpha$ platelets with certain stretching directions are favorable for nucleation and growth due to variant selection under the applied force. According to the above SEM/TEM observations on the deformed lamellar microstructure, the detailed process of the evolution of $\alpha / \beta$ lamellae under the hot compression can be shown in Fig. 8(b) and described below.

When lower compression strain is applied, severe kinking of $\alpha / \beta$ lamellae occurred in the $\alpha / \beta$ lamellar colonies under the complicated shear stress state (upper half of Fig. 8(b)). It should also be noted that the kinking of $\alpha / \beta$ lamellae should be related to the original orientation of the lamellae relative to the loading direction [27]. Bieler et al. [28] observed that globularization is difficult in colonies having their $c$-axes parallel to the compression direction so that the prism and basal slip systems cannot be activated. And then, globularization (fragmentation) of the $\alpha / \beta$ lamellae may occur under the effect of dense dislocation configurations with the increased strain. Actually, the kinking of $\alpha / \beta$ lamellae is the preparatory stage of fragmentation.

When higher compression strain is applied, the flat-smooth cutting might form directly and across $\alpha / \beta$ lamellae gradually (lower half of Fig. 8(b)). Thus, the $\alpha$ platelets are easier to be fragmented under the high shear strain. Actually, the initiation of the flat-smooth cutting might be accompanied by the fragmentation of $\alpha / \beta$ lamellar around the fracture surface by intense dislocation activities. Refs. [9,29] described that the refinement of grains in deformation bands as a recrystallization behavior. However, the $\alpha / \beta$ lamellar structures are really thin with $\sim 20 \mathrm{~nm}$ in width in the present work. Thus, the fragmentation and globularization is speculated to play an important role in the grain refinement process. Moreover, the increased deviation from BOR of $\alpha / \beta$ due to the deformation would accelerate the kinetics of $\alpha$ lamellae fragmentation [30]. The fragmentized $\alpha / \beta$ lamellae might be further broken and rotated in order to release the stresses, which led to the formation of randomly orientated nanocrystallites. With the continuous increase of the strain, the adjacent $\alpha$ precipitates and $\beta$ blocks would be swept into the localized strain region. In other words, the fracture

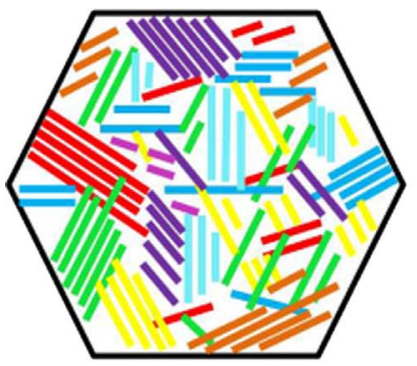

(a)

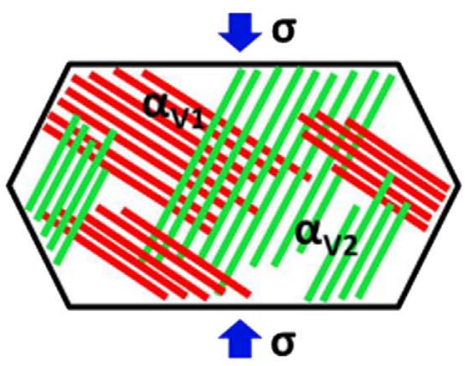

(b)

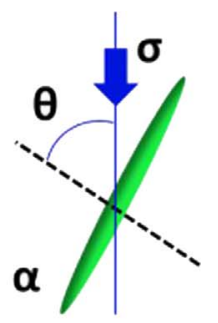

Fig. 7. Illustration of $\alpha$ variant selection mechanism during the hot deformation process: (a) all $\alpha$ variants nucleate theoretically with equal probability during $\beta \rightarrow \alpha$ phase transformation; (b) $\alpha$ variant selection during the hot deformation; (c) schematic of $\alpha$ phase under the external stress. ( $\alpha$ phase variants are represented by various colors.) (For interpretation of the references to color in this figure legend, the reader is referred to the web version of this article.)

(c) 


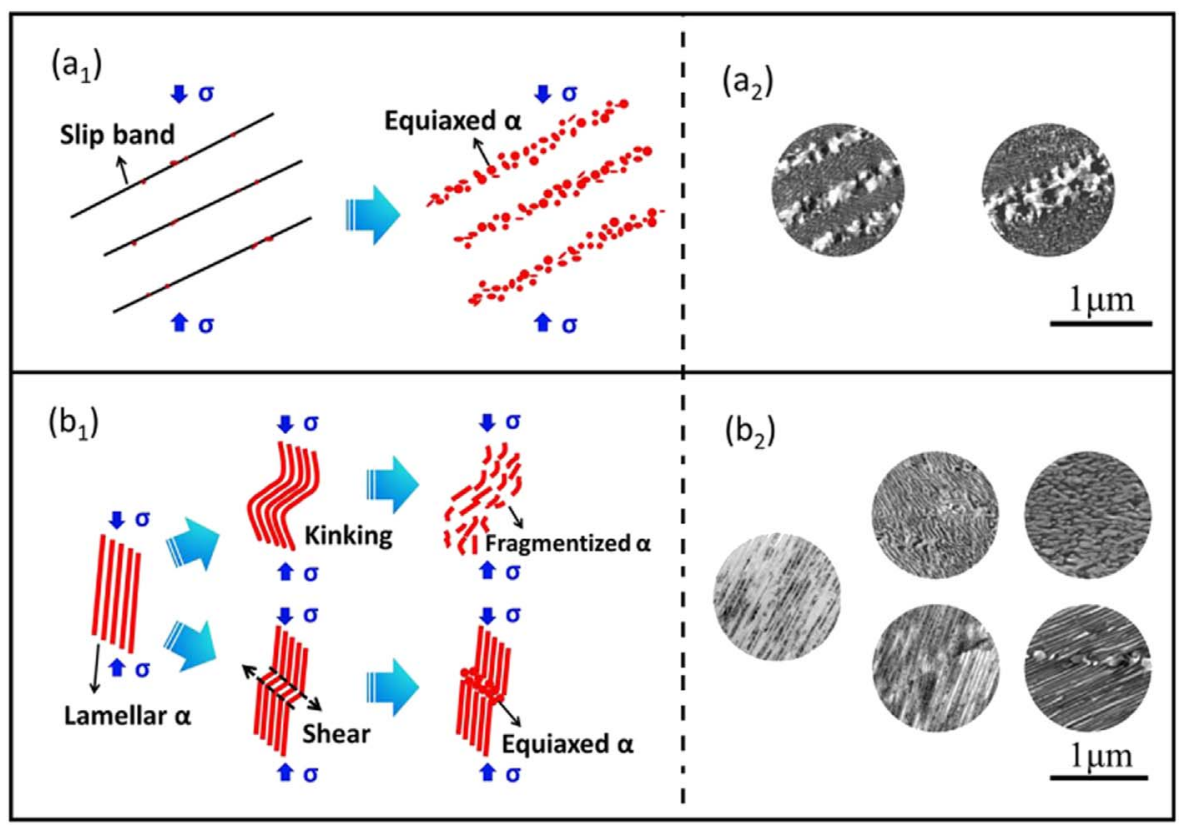

Fig. 8. Schematic diagram of the dynamic precipitation and evolution of $\alpha$ phase during the isothermal deformation: (a) $\alpha$ phase in slip bands; (b) $\alpha$ lamellae colony.

surface thickens at the expense of the surrounding $\alpha$ precipitates and $\beta$ blocks.

It is believed that the flat-smooth cutting may not develop in $\alpha$ colony until a given applied stress is large enough to make the activated dislocations in the $\alpha$ platelet piling up at the $\alpha / \beta$ interface, which could cut through the interface and glide into the $\beta$ lamella. Such a applied stress to trigger cutting should be associated with the scale of the lamella and the deformation temperature [31]. On the other hand, only the kinking of $\alpha / \beta$ lamellar happened in somewhere when the applied stress is not up to the critical value $\left(\sigma_{\mathrm{c}}\right)$ [32]. This evaluation is one of the causes for the flow softening and play an important role in the workability and formability of the alloy during hot working process, which is not only found in the present work but also is often observed in $\alpha / \beta$ lamellar structured Ti alloys.

\section{Conclusions}

The microstructure evolution and variant selection mechanism of $\alpha$ phase during the thermo-mechanical treatment at low temperature were studied in the Ti-5553 metastable $\beta$ titanium alloy with single $\beta$ phase initial microstructure. The following main conclusions can be drawn:

(1) The nano/ultrafine-trimorphic structure, consisting of equiaxed $\alpha$, irregular fragmentized $\alpha$ and lamellar $\alpha$, can be successfully produced dynamically in a Ti-5553 alloy through warm deformation of a single $\beta$ initial microstructure. All of these varied $\alpha$ precipitates were formed dynamically during the warm deformation process, which is distinctively different with the previous related studies.

(2) Ultrafine equiaxed $\alpha / \beta$ grains do not respect BOR were observed in the slip bands together with the remaining regions consisting of the lamellar $\alpha$ structure maintaining BOR with $\beta$ matrix. A dense array of irregular $\alpha$ grains could be detected in some places, which mainly attributed to the fragmentation of the lamellar $\alpha$ structure. Moreover, there is significant variation in the proportion and distribution of the $\alpha$ precipitates along the compression disc radius and thickness depending on the amount of deformation.

(3) Only two or three $\alpha$ variants would nucleate in local $\beta$ matrix under the hot deformation condition due to the drastic strain induced variant selection.

\section{Acknowledgements}

This work was supported by the National Natural Science Foundation of China (No. 51371143) and Major State Research Development Program of China (2016YFB0701303).

\section{References}

[1] Premkumar Manda, Vajinder Singh, Uday Chakkingal, A.K. Singh, Development of a precipitates in metastable Ti-5Al-5Mo-5V-3Cr and similar alloys, Mater. Charact. 120 (2016) 220-228.

[2] R. Boyer, R.D. Briggs, The use of $\beta$ titanium alloys in the aerospace industry, J. Mater. Eng. Perform. 14 (2005) 681-685.

[3] M. Salib, J. Teixeira, L. Germain, E. Lamielle, N. Gey, E. Aeby-Gautier, Influence of transformation temperature on microtexture formation associated with $\alpha$ precipitation at $\beta$ grain boundaries in a $\beta$ metastable titanium alloy, Acta Mater. 61 (2013) 3758-3768.

[4] G. Choi, K. Lee, Effect of cold rolling on the microstructural evolution of new $\beta$ typed Ti-6Mo-6V-5Cr-3Sn-2.5Zr alloys, Mater. Charact. 123 (2017) 67-74.

[5] M.J. Lai, C.C. Tasan, D. Raabe, Deformation mechanism of $\omega$-enriched Ti-Nb-based gum metal: dislocation channeling and deformation induced $\omega-\beta$ transformation, Acta Mater. 100 (2015) 290-300.

[6] N.G. Jones, R.J. Dashwood, D. Dye, Thermomechanical processing of Ti-5Al-5Mo5V-3Cr, Mater. Sci. Eng. A 490 (2008) 369-377.

[7] S. Nag, Y. Zheng, R.E.A. Williams, A. Devaraj, A. Boyne, Y. Wang, P.C. Collins, G.B. Viswanathan, J.S. Tiley, B.C. Muddle, R. Banerjee, H.L. Fraser, Acta Mater. 60 (18) (2012) 6247-6256.

[8] F. Prima, P. Vermaut, G. Texier, D. Ansel, T. Gloriant, Evidence of $\alpha$-nanophase heterogeneous nucleation from $\omega$ particles in a $\beta$-metastable Ti-based alloy by highresolution electron microscopy, Scr. Mater. 54 (4) (2006) 645-648.

[9] Q. Chao, P.D. Hodgson, H. Beladi, Ultrafine grain formation in a Ti-6Al-4V alloy by thermomechanical processing of a martensitic microstructure, Metall. Mater. Trans. A 45 (5) (2014) 2659-2671.

[10] T. Furuhara, T. Maki, Variant selection in heterogeneous nucleation on defects in diffusional phase transformation and precipitation, Mater. Sci. Eng. A 312 (1) (2001) 145-154.

[11] S.L. Semiatin, T.R. Bieler, The effect of alpha platelet thickness on plastic flow during hot working of TI-6Al-4V with a transformed microstructure, Acta Mater. 49 (2001) 3565-3573.

[12] R. Shi, Y. Wang, Variant selection during a precipitation in Ti-6Al-4V under the influence of local stress-a simulation study, Acta Mater. 61 (16) (2013) 6006-6024.

[13] M. Klimova, S. Zherebtsov, G. Salishchev, S.L. Semiatin, Influence of deformation on the Burgers orientation relationship between the $\alpha$ and $\beta$ phases in Ti-5Al-5Mo5V-1Cr-1Fe, Mater. Sci. Eng. A 645 (2015) 292-297.

[14] W.G. Burgers, On the process of transition of the cubic-body-centered modification into the hexagonal-close-packed modification of zirconium, Physica 1 (1934) $561-586$.

[15] A. Morawiec, Automatic orientation determination from Kikuchi patterns, J. Appl. Crystallogr. 32 (1999) 788-798.

[16] A. Morawiec, J.J. Fundenberger, E. Bouzy, J.S. Lecomte, EP-a program for determination of crystallite orientations from TEM Kikuchi and CBED diffraction patterns, J. Appl. Crystallogr. 35 (2002) 287. 
[17] H.J. Bunge, C. Esling, J. Muller, The influence of crystal and sample symmetries on the orientation distribution function of the crystallites in polycrystalline materials, Acta Crystallogr. A 37 (1981) 889-899.

[18] N. Clément, A. Lenain, P.J. Jacques, Mechanical property optimization via microstructural control of new metastable beta titanium alloys, JOM 59 (2007) 50-53.

[19] D. Bhattacharyya, G.B. Viswanathan, R. Denkenberger, D. Furrer, H.L. Fraser, The role of crystallographic and geometrical relationships between $\alpha$ and $\beta$ phases in an a/ß titanium alloy, Acta Mater. 51 (16) (2003) 4679-4691.

[20] S.M.C. Van Bohemen, A. Kamp, R.H. Petrov, L.A.I. Kestens, J. Sietsma, Nucleation and variant selection of secondary $\alpha$ plates in a $\beta$ Ti alloy, Acta Mater. 56 (20) (2008) 5907-5914.

[21] Z.Y. Song, Q.Y. Sun, L. Xiao, J. Sun, L.C. Zhang, Precipitation behavior and tensile property of the stress-aged Ti-10Mo-8V-1Fe-3.5Al alloy, Mater. Sci. Eng. A 528 (12) (2011) 4111-4114.

[22] J.D. Eshelby, The determination of the elastic field of an ellipsoidal inclusion and related problems, Proc. R. Soc. A 241 (1957) 376-396.

[23] W.F. Hosford, S.P. Agrawal, Effect of stress during aging on the precipitation of $\theta^{\prime}$ in Al-4 Wt pct Cu, Metall. Trans. A. 6 (1975) 487-491.

[24] A. Dehghan-Manshadi, R.J. Dippenaar, Development of $\alpha$-phase morphologies during low temperature isothermal heat treatment of a Ti-5Al-5Mo-5V-3Cr alloy, Mater. Sci. Eng. A 528 (3) (2011) 1833-1839.
[25] J. Luo, S.F. Liu, M.Q. Li, Quantitative analysis of microstructure and deformation mechanisms during isothermal compression of Ti-5Al-5Mo-5V-1Cr-1Fe alloy, Mater. Charact. 108 (2015) 115-123.

[26] J.K. Fan, J.S. Li, H.C. Kou, K. Hua, B. Tang, Y.D. Zhang, Influence of solution treatment on microstructure and mechanical properties of a near $\beta$ titanium alloy Ti-7333, Mater. Des. 83 (2015) 499-507.

[27] L. Germain, N. Gey, M. Humbert, P. Bocher, M. Jahazi, Analysis of sharp microtexture heterogeneities in a bimodal IMI 834 billet, Acta Mater. 53 (13) (2005) 3535-3543.

[28] T.R. Bieler, S.L. Semiatin, The origins of heterogeneous deformation during primary hot working of Ti-6Al-4V, Int. J. Plast. 18 (9) (2002) 1165-1189.

[29] Y. Xu, J. Zhang, Y. Bai, M.A. Meyers, Shear localization in dynamic deformation: microstructural evolution, Metall. Mater. Trans. A 39 (4) (2008) 811-843.

[30] S.L. Semiatin, D.U. Furrer, Fundamentals of modeling for metals processing, ASM Handbook, ASM International, Materials Park, Ohio, 2009, pp. 536-552.

[31] Y.P. Li, X.F. Zhu, J. Tan, B. Wu, G.P. Zhang, Two different types of shear-deformation behaviour in Au-Cu multilayers, Philos. Mag. Lett. 89 (2009) 66-74.

[32] B. Zhang, L.M. Lei, X.L. Jiang, Z.M. Song, X. Huang, G.P. Zhang, On temperature and strain rate dependent strain localization behavior in Ti-6.5Al-3.5Mo-1.5Zr-0.3Si alloy, J. Mater. Sci. Technol. 29 (3) (2013) 273-278. 